\title{
Innovation of Talent Training Mode for Undergraduates Majored in Energy Under the "Carbon Neutralization" Target
}

\author{
Yining WANG ${ }^{\mathrm{a}, 1}$ and Wei RONG ${ }^{\mathrm{b}}$ \\ a Organization Department, Northwestern Polytechnical University, Xi'an, Shaanxi, \\ China \\ ${ }^{\mathrm{b}}$ Unmanned System Research Institute, Northwestern Polytechnical University, Xi 'an, \\ Shaanxi, China
}

\begin{abstract}
In September 22, 2020, Xi Jinping said at the seventy-fifth general debate of the UN General Assembly that China will enhance the national independent contribution, and strive to achieve the peak of carbon dioxide emissions by 2030 , and strive to achieve carbon neutralization by 2060 . Under the goal of carbon peak and carbon neutralization, the implementation of carbon emission reduction is an important strategy for China to achieve green and low-carbon development, but also faces major challenges "The Fourteenth Five Year Plan" Period is an important window period for scientific and technological innovation to realize the transformation of carbon dioxide emission growth rate. Only with the support of scientific and technological innovation can China be expected to achieve the goal of carbon peak and carbon neutralization on schedule. This paper attempts to study how to innovate the energy undergraduate talent training mode under the goal of "carbon neutral" from the aspects of the current situation of talent training, the analysis of talent training objectives, and the path analysis of talent training mode innovation.
\end{abstract}

Keywords. Carbon neutralization, carbon dioxide emissions, talent training

\section{Current Situation of Talent Training for Undergraduates Majored in Energy}

With the impact of human activities on global climate, the impact of climate crisis is becoming serious increasingly. The global average temperature is rising at an unprecedented rate [1]. In September 2020, China announced the goal of achieving carbon peak by 2030 and achieving carbon neutralization by 2060 years. This is not only a national policy that actively responded to climate change in China, but also a national strategy based on scientific argumentation. It is an action goal starting from reality and a farsighted long-term development strategy. Colleges and universities shoulder the important functions of talent training, scientific research, social service, cultural heritage and international exchange and cooperation. How to innovate the talent training mode for undergraduates majored in Energy under the "Carbon Neutralization" target [2], is an important topic to achieve the goal of innovative talents training.

In order to understand the current situation of Energy and Power Engineering

1 Corresponding Author, Yining WANG, Organization Department, Northwestern Polytechnical University, Xi’an, Shaanxi, China; Email: wangyining@nwpu.edu.cn. 
professional training, the author investigated the talent training objectives and requirements at home and abroad, including University of California, Berkeley, Georgia Institute of technology, University of Michigan at Ann Arbor, University of Pennsylvania and University of Utah, Tsinghua University, Xi'an Jiaotong University, Zhejiang University, Shanghai Jiaotong University, Huazhong University of Science and Technology, Tianjin University, Southeast University, Northwestern Polytechnical University etc. The result is as follows:

First, in terms of specialty setting. For foreign universities, the major of Energy and Power Engineering is usually set up in Engineering College or Mechanical College (Department), mainly focuses on Thermal Fluid Science, Energy System and Energy Engineering [3]. The enrollment scale of these majors is about 35-80. In China, the major is mainly set up in the College of Energy and Power, Energy and Environment or Mechanical Engineering, with an enrollment of about 90-430, which is far more than its foreign counterpart.

Second, in terms of training objectives. The training objectives of both domestic universities and foreign universities, focus on independence, innovation and contribution to society. Foreign universities emphasize the motivation and ability of "lifelong learning". Domestic universities have more detailed training objectives, highlight applicable fields of talents and emphasize the "international vision".

Third, in terms of curriculum and credit setting. The basic courses of this major are similar at home and abroad, including mathematics, physics, chemistry, computer, thermodynamics, fluid mechanics and heat transfer. Elective courses in this major aboard is relatively large.

\section{Analysis of the Talent Training Target of Undergraduates Majored in Energy under the Goal of "Carbon Neutralization"}

What is "Carbon Peak" and "Carbon Neutralization"? When carbon reaches the peak, carbon dioxide emissions will no longer increase and then decrease slowly after reaching the peak. "Carbon Neutralization" means net zero emission. The carbon emissions necessary for human economic and social activities are captured and stored by forest carbon sink and other artificial technology or engineering means, making the net increase of greenhouse gases emitted into the atmosphere zero. Innovative talents mainly refer to those who have innovative consciousness, innovative spirit, innovative thinking, innovative ability and can achieve innovative results. Under the goal of "Carbon Neutralization", the talent training of undergraduates majored in Energy should be committed to the development, production, conversion and utilization of high efficiency and clean energy [4]. Only cultivating high-level talents with solid theoretical foundation, strong ability of practice, adaptation and innovation, high moral quality and cultural quality, can meet the social needs of scientific research, design, teaching, engineering technology and management in the field of Energy Power discipline, and provide talent support for solving energy problems in China.

Firstly, cultivating high-quality compound talents with strong engineering practice ability, strong innovation ability and international competitiveness is necessary. Not only solid professional knowledge, but also seizing the strategic opportunity of national energy revolution and ecological civilization construction is significant [5].

Secondly, we should adhere to the combination of teaching and scientific research, emancipate our minds, scientifically plan, deepen the reform of education, highlight the 
characteristics, explore the coordinated development mode of teachers, disciplines and bases based on talent training, and train professional talents with "thick foundation, broad specialty, strong practice and innovation".

Thirdly, according to the national medium and long-term science and technology development plan, we should serve the major needs of national modernization and also cultivate high-level compound talents with strong sense of social responsibility, good psychological quality and humanistic quality, solid basic theory, broad professional knowledge, strong sense of innovation and team spirit, and broad international vision [6]. Furthermore, we also need to cultivate high-quality application-oriented talents with continuous learning ability, entrepreneurial spirit and the ability to solve complex energy and power engineering problems, especially the engineering problems of energy conversion and cascade utilization, heat and mass transfer and fluid flow, clean combustion and collaborative governance, process energy saving and process control, new energy and artificial environment in "process industry".

\section{Path Analysis of Talent Training Mode Innovation for Undergraduates Majored in Energy under "Carbon Neutralization" Target}

\subsection{Social Level: Further Optimization of the Market System and Exploration of Development Based on Demand}

The government attaches great importance to environmental protection, integrates the construction of ecological civilization into the "five in one" overall layout of the cause of socialism with Chinese characteristics, vigorously promotes green, low-carbon and sustainable development, conscientiously fulfills the obligations of international environmental treaties in the fields of climate change, biodiversity and chemicals, and has achieved remarkable results. The government should strengthen macro-control, speed up the transformation and upgrading and layout adjustment of relevant industrial enterprises in combination with the goals of "Carbon Neutralization" and ecological civilization construction, and issue supportive policies to promote the transformation and upgrading, so as to provide a superior environment for college students' enrollment and employment. At the same time, due to the uneven distribution of resources in China, we should strengthen the implementation of preferential policies, especially for industries and regions with relatively difficult employment or employment conditions at the grassroots level, we should support them from material security and development channels, improve their sense of career acquisition, increase their attractiveness and guide energy undergraduates to face grass-roots employment. We should combine policy incentives with ideological education [7], guide and help college students to go to the grassroots level in Western China where there is a serious shortage of talents, and establish a longterm mechanism for Grassroots Employment.

\subsection{University Level: The Reform of Teaching Methods and the Innovation of Personnel Training}

Education and economy must develop harmoniously. The absence of education will have a serious impact on the economy. We should strengthen the University's response speed and ability to the external market, give universities greater autonomy, so that universities can adjust the professional settings and enrollment scale in time according to the 
economic development and the demand of labor market, so as to meet the needs of talents for economic development [8]. In view of the unreasonable division of specialty setting, the disjunction with social demand, the deviation of training mode and unreasonable talent positioning, the following four suggestions are put forward.

First, we should adjust the professional and curriculum settings, and implement the "six in one" talent training mode. At present, many colleges and universities, on the basis of adhering to the level of elite education, are guided by employment, and scientifically set up majors and courses according to the market demand. They should strengthen the cultivation of practical links, actively adjust the curriculum settings to make energy undergraduate education adapt to the needs of the labor market, adapt to the changes of the situation and go ahead of the changes. It is conducive to improving their competitiveness in the employment market "Six in one" talent training mode: a mode of training applied talents through six links of cognition practice, production practice, curriculum design, professional competition, graduation practice and graduation design, which enables students to have solid theoretical knowledge and strong professional skills, laying a solid foundation for students' employment and future development.

Second, we should develop characteristic disciplines in combination with local economic characteristics. Under the background of "double first-class" construction, to enhance the competitiveness of colleges and universities, we must strengthen the construction of characteristics and closely serve the development of local economy. In particular, engineering colleges should be closely integrated with local social development, so as to meet the needs of economic development for all kinds of talents. Energy talents are closely related to local economic development, and any industry cannot do without energy and power. Energy majors should also keep pace with the times, integrate the latest achievements of the current era, open relevant elective courses, and highlight the freshness of course learning.

Third, we should promote the school enterprise joint training mode. According to the characteristics of student training, universities and employers jointly sign a joint training agreement. On this basis, the joint training mode is adopted according to the talent needs of enterprises. Both sides jointly provide teachers. Universities are responsible for theoretical teaching, and enterprises are responsible for practice and internship, At the same time, enterprises can provide better living conditions and scholarships and other incentive measures for the students in the joint training class. After the joint training class is finished, the qualified students can directly enter the enterprise to work. To carry out the "order type" talent training, we can tailor it according to the special needs of the employing units, and carry out the talent training work pertinently.

\subsection{Student Level: The Improvement of Employment Quality and the Change of Traditional Employment Concept}

Undergraduates majored in Energy must understand and master the connotation of "Carbon Neutralization" target, establish development goals, do well in personal career development planning, and strive to become excellent talents with market competitiveness.

First, undergraduates majored in energy should evaluate themselves objectively. Students should make it clear that the current undergraduates majored in energy are not "scarce" talents, and pay attention to improving their own development characteristics, so as to occupy a favorable position in the fierce job market [9].

Second, strengthen the training of professional and basic skills. During the study 
period, undergraduates majored in energy should make great efforts to study, so that they can have a solid theoretical foundation in the fields of energy conversion and utilization and thermal environmental protection. At the same time, they should consciously expand the knowledge of frontier disciplines, and have broad knowledge of natural science, humanities and Social Sciences, as well as broad theoretical foundation in heat, mechanics, electricity, machinery, automatic control, etc. Both undergraduate and graduate students are required to consciously participate in social practice competitions such as science and technology project approval, energy conservation and emission reduction, and innovative experiments, so as to improve their practical ability and apply the learned knowledge to practice.

Third, we should enhance the competitiveness of employment. Undergraduates majored in energy should have a clear understanding of their own abilities, comprehensively evaluate their strengths and weaknesses, constantly strengthen their own construction, actively participate in various activities [10], and improve their comprehensive abilities, such as organization and coordination ability, expression ability and ability to deal with emergencies. In the final analysis, they should enhance their core competitiveness.

\section{Conclusion}

"Carbon Neutralization" is a broad and profound economic and social systematic change. It is necessary to clarify the talent training objectives of undergraduates majored in energy, and train high-level compound talents with strong sense of social responsibility, good psychological quality and humanistic quality, solid basic theory, broad professional knowledge in the field of energy, strong sense of innovation and team spirit, and broad international vision, contribute talents to achieve the goal of "Carbon Peak" and "Carbon Neutralization" vision in China.

\section{References}

[1] Ren Y and Chen A 2017 On innovative talents and their behavior characteristics Educational Research 1 150 .

[2] Wu A, Hou Y and Yang Q 2017 Accelerating development and construction of emerging engineering, taking initiative to adapt to and lead the new economy Research in Higher Education of Engineering 14.

[3] Cheng X, Zhang S and Zhang Y 2018 Exploration and practice of a new model of excellent engineer practice education for the major of energy and power engineering China Modern Educational Equipment 21104.

[4] Zhuang G 2021 Roadmap of achieving carbon peak goal and carbon neutrality vision Shanghai Energy Conservation 6551.

[5] Men Z, Li C and Gao W 2021 Collaborative training mode of innovation and entrepreneurship ability of students majoring in artificial intelligence under the background of emerging engineering education Journal of Higher Education Research 110.

[6] Guo M and Xia D 2018 Construction and practice of innovative talents training system in thermal engineering China Metallurgical Education 596.

[7] Kong X, Li Y and Yi Q 2018 Reform and practice of talent training facing diversified of energy and power engineering specialty Journal of Architectural Education in Institutions of Higher Learning 215.

[8] Wang Z 2020 Humble opinion on the history, current situation and development of discipline construction China Higher Education Research 1118.

[9] Feng Y and Zheng X 2020 Discussion on practical teaching method of energy and power engineering in general universities Guangdong Chemical Industry 16245.

[10] Chen W, Wu C and Yu J 2011 The system analysis of innovative training model Science Technology and Industry 1118. 